\title{
Estética em Ortodontia: seis linhas horizontais do sorriso
}

\author{
Carlos Alexandre Câmara*
}

\begin{abstract}
Resumo
Introdução: a análise do sorriso é uma importante etapa para o diagnóstico, planejamento, tratamento e prognóstico de qualquer tratamento odontológico envolvido com objetivos estéticos. A avaliação das características intrínsecas do sorriso é um procedimento necessário para que se possa atuar de forma consistente nos tratamentos ortodônticos, necessitando para isso que sejam reconhecidos os componentes e os fatores que interferem nessas características. Objetivo: o objetivo desse trabalho é apresentar seis linhas horizontais do sorriso e a sua importância para a obtenção de resultados desejados nos tratamentos ortodônticos. Conclusão: a análise das seis linhas horizontais do sorriso facilita o entendimento das características intrínsecas que interferem na estética bucal. Além disso, a harmonização dessas linhas traz para cada profissional uma maior chance de sucesso nos seus tratamentos que incluam objetivos estéticos.
\end{abstract}

Palavras-chave: Ortodontia. Estética em Ortodontia. Estética dentária. Estética bucal. Sorriso.

\section{INTRODUÇÃO}

A obtenção de um sorriso bonito é sempre o objetivo principal de qualquer tratamento estético odontológico. Afinal, é a beleza do sorriso que fará a diferença entre o resultado estético aceitável ou agradável em qualquer tratamento. Entretanto, apesar da sua importância, as características intrínsecas desse são pouco discutidas. Muito se fala das consequências clínicas dos procedimentos odontológicos sobre o sorriso, mas pouco se avalia as suas características intrínsecas. Características essas que algumas vezes podem ser alteradas e outras não, pois são partes integrantes do próprio indivíduo, e a Odontologia não tem alcance sobre elas, restando apenas a sua avaliação.

Avaliar o belo é sempre subjetivo. No entanto, necessitamos de ferramentas adequadas para suprir a dificuldade dessa subjetividade. $\mathrm{Na}$ Ortodontia, não é suficiente apenas perceber o que interfere no sorriso, é necessário diagnosticar o que se encontra fora da normalidade, para que se possa estabelecer um plano de tratamento. Assim como nos problemas funcionais seguimos condutas que nos levam ao diagnóstico das anomalias, os problemas estéticos também necessitam de parâmetros para que encontremos os defeitos. Na busca da visualização de problemas, várias regras e suposições são criadas, levando algumas vezes à subestimação de defeitos ou à supervalorização de regras, criando paradigmas que não são sustentados por dados científicos comprovados. A própria essência da Odontologia Estética, que envolve critérios artísticos, contribui

\footnotetext{
* Especialista em Ortodontia (FO-UERJ). Diplomado pelo Board Brasileiro de Ortodontia e Ortopedia Facial.
} 
para esse fato. $\mathrm{O}$ uso de mecanismos simples e confiáveis pode, se não eliminar os erros de conduta, melhorar as possibilidades de acerto.

Algumas ferramentas podem ser utilizadas para tal propósito. O Diagrama de Referências Estéticas Dentárias (DRED) é um meio auxiliar de diagnóstico que se presta adequadamente a esse fim. Esse diagrama é constituído de seis caixas que englobam os incisivos e caninos superiores; e os seus limites irão ser específicos para cada referência estética. A sua finalidade é dar uma noção exata dos posicionamentos e proporções que os dentes guardam entre si e também a relação desses com a gengiva e os lábios ${ }^{5}$. Concebido originalmente para auxiliar a visão dos dentes anteriores superiores, o DRED, acrescido de novas informações, cria condições para uma avaliação objetiva do sorriso, facilitando o diagnóstico e prognóstico estético. Portanto, será o objetivo desse trabalho apresentar as novas características do DRED e a sua participação nas "seis linhas horizontais do sorriso", que irão auxiliar de forma muito prática o diagnóstico, tratamento e prognóstico da estética bucal.

\section{DIAGRAMA DE REFERÊNCIAS ESTÉTICAS DENTÁRIAS - DRED (novas características)}

O Diagrama de Referências Estéticas Dentárias (DRED) foi criado para facilitar a visualização dos dentes anteriores superiores, sugerindo o que deve ser criado ou alcançado com esses dentes,

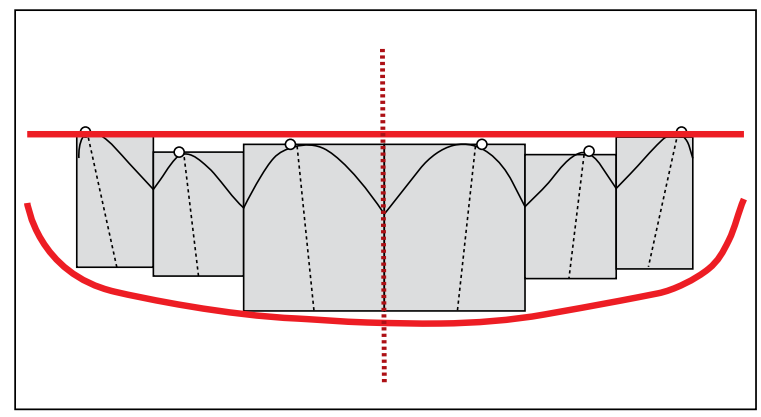

FIGURA 1 - Diagrama de Referências Estéticas Dentárias (DRED). objetivando a melhor estética dentária. A finalidade desse diagrama é dar uma noção exata dos posicionamentos e proporções que os dentes guardam entre si, e também a relação desses com a gengiva e os lábios, numa vista frontal. Como já foi dito, esse diagrama é constituído de seis caixas que englobam os incisivos e caninos superiores; e os seus limites irão ser específicos para cada referência dentária. Cada caixa engloba o seu respectivo dente, obedecendo os seus limites (Fig. 1). Embora essas caixas possam servir de referência nos vários planos de observação, o DRED é avaliado em uma vista de $90^{\circ}$ com relação ao plano frontal, ou seja, perpendicular a esse plano. A sua utilização facilita o planejamento e a visualização do melhor posicionamento estético dos dentes anteriores, sendo o seu objetivo fornecer informações que auxiliam nas suas reorganizações e reestruturações, quando esses dentes necessitam ser reposicionados e/ou restaurados. Entretanto, embora a concepção original do DRED sirva para auxiliar de forma muito prática a avaliação da estética bucal, algumas referências de estruturas dentárias, gengivais e labiais podem ser acrescentadas no seu formato, melhorando e facilitando a visualização do sorriso.

No seu formato original, o DRED faz referência aos zênites gengivais, que são os pontos mais apicais do contorno gengival. Na presente reavaliação serão acrescentadas as localizações das extremidades das papilas gengivais (pontas da papilas) e enfatizados os pontos de contato (Fig. 2).

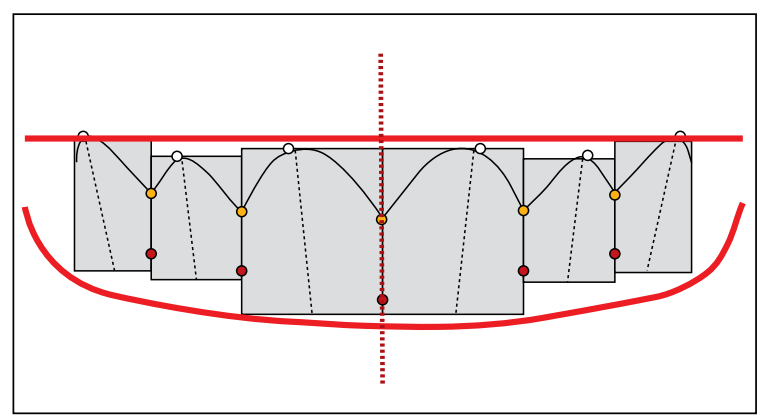

FIGURA 2 - DRED com novos pontos de referência: pontos de contato e pontas das papilas gengivais. 
A união desses pontos formará linhas que darão referências avaliativas na análise do sorriso. Sendo assim, o DRED terá intrinsicamente quatro linhas, formadas pelas seguintes estruturas (Fig. 3):

- linha cervical - zênites gengivais;

- linha papilar - pontas das papilas;

- linha dos pontos de contato - pontos de contato;

- linha incisal - bordas incisais (linha incisal).

A relação da linha papilar com a linha dos pontos de contato criará uma faixa que será chamada de faixa dos conectores, em referência ao conceito dos conectores dentários ${ }^{19}$. Essa faixa, formada pelas duas linhas (papilas e pontos de contato) somadas às linhas cervical e incisal, dará, em uma vista frontal, as referências dentárias horizontais do sorriso.

As outras duas linhas que fazem parte do conjunto das linhas horizontais dos sorriso são a linha do lábio superior e a linha do lábio inferior. Essas linhas labiais, junto com as linhas dentárias e gengivais, irão integrar o conjunto das seis linhas horizontais do sorriso (Fig. 4).

\section{LINHA CERVICAL}

A linha cervical ou gengival é formada a partir da união dos zênites dos caninos, incisivos laterais e incisivos centrais superiores. Sendo o ponto mais apical do contorno gengival, o

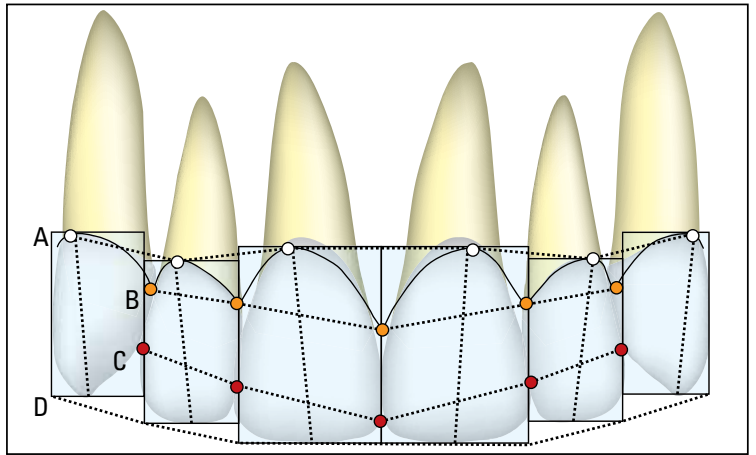

FIGURA 3 - Linhas de referências estéticas: Linha Cervical (A); Linha Papilar (B); Linha dos pontos de contato (C) e Linha Incisal (D). zênite, nos dentes superiores, está normalmente localizado distalmente ao longo eixo dentário. Entretanto, essa regra nem sempre se aplica aos incisivos laterais superiores. Nesses dentes, o limite gengival pode estar centrado no longo eixo. Como os zênites dos caninos superiores estão, na maioria das vezes, mais altos do que os incisivos laterais, e mais ou menos na mesma altura dos incisivos centrais, a linha cervical fica com um aspecto convexo em relação ao plano oclusal (Fig. 5). Essa seria a forma ideal da linha cervical. Quando os incisivos laterais se posicionam mais apicalmente, na mesma altura de caninos e incisivos centrais, essa linha passa a ser plana (Fig. 6). Quando o contorno gengival dos caninos está abaixo dos laterais, a linha formada será côncava (Fig. 7). A linha cervical côncava é a forma menos agradável entre as três possibilidades.

Existirão situações nas quais as alturas dos dentes anteriores estarão assimétricas e levarão à formação de uma linha cervical assimétrica (Fig. 8). Deve ficar claro que o posicionamento dos zênites gengivais pode variar bastante entre os dentes e cada indivíduo terá uma linha cervical com formato próprio, sendo praticamente impossível a representação de todas as possibilidades. A nomenclatura utilizada para a linha cervical (plana, côncava e convexa) serve apenas como referência

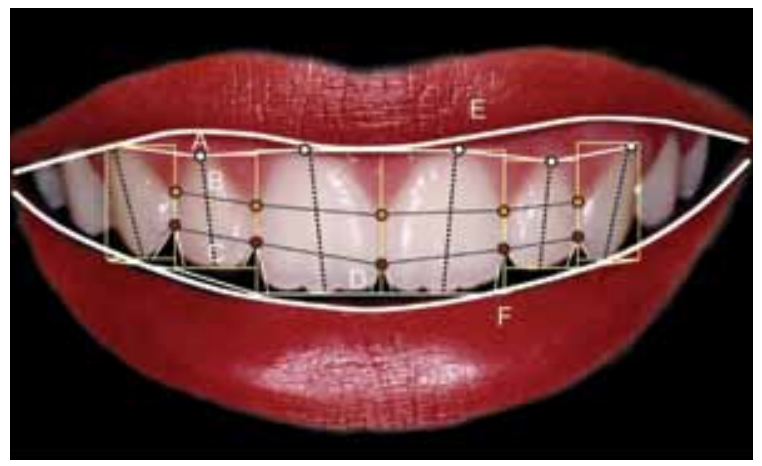

FIGURA 4 - As seis linhas horizontais do sorriso: Linha cervical (A); Linha papilar (B); Linha dos pontos de contato (C); Linha incisal (D); Linha do lábio superior (E) e Linha do lábio inferior (F). 
avaliativa. A variação da altura cervical dos dentes estará sujeita às condições periodontais de cada dente, assim como o tamanho dentário, as suas inclinações, o padrão eruptivo e a inclinação do plano oclusal.

\section{LINHA INCISAL}

A linha incisal segue as bordas dos dentes anterossuperiores. O ideal é que nos pacientes jovens, em uma vista frontal, as bordas incisais do incisivos centrais estejam abaixo das bordas dos incisivos laterais e caninos. Nessa configuração, a forma da linha incisal lembra o desenho de um "prato fundo" (Fig. 9). A alteração do posicionamento das bordas incisais modifica esse desenho. Quando a incisal dos incisivos centrais não mais estiver abaixo dos laterais, haverá uma alteração do desenho, passando esse a ser chamado de "prato raso" ou, dependendo

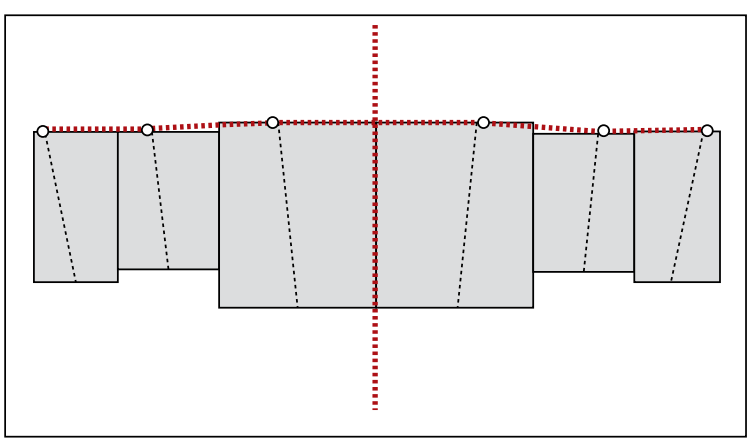

FIGURA 6 - Forma plana da linha cervical.

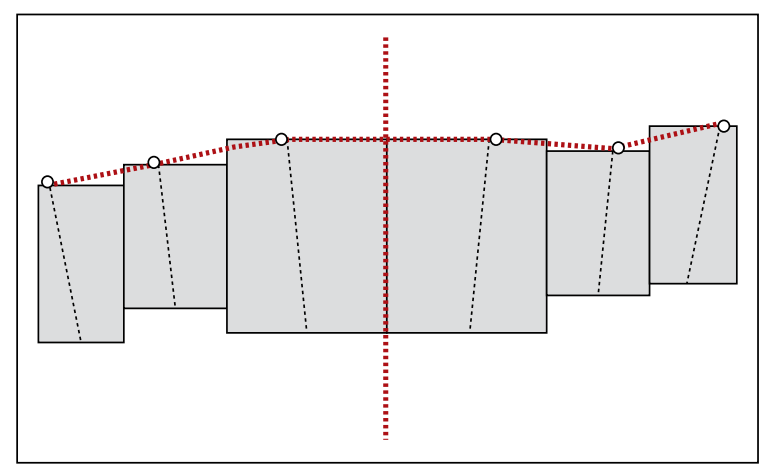

FIGURA 8 - Linha cervical assimétrica. da relação, "prato invertido". Normalmente, a configuração da linha incisal está relacionada com a idade. Desgastes dos incisivos centrais ocorrem com o tempo, levando a essas alterações. Entretanto, não só as alterações causadas por desgastes afetam o desenho da linha incisal. Assim como a linha cervical,

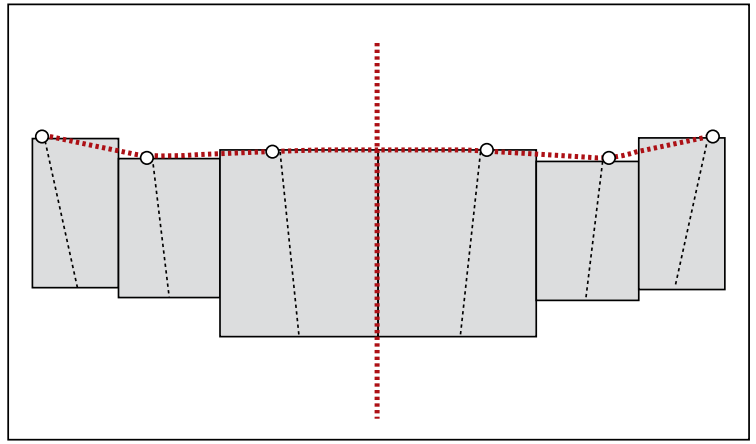

FIGURA 5 - Forma convexa da linha cervical.

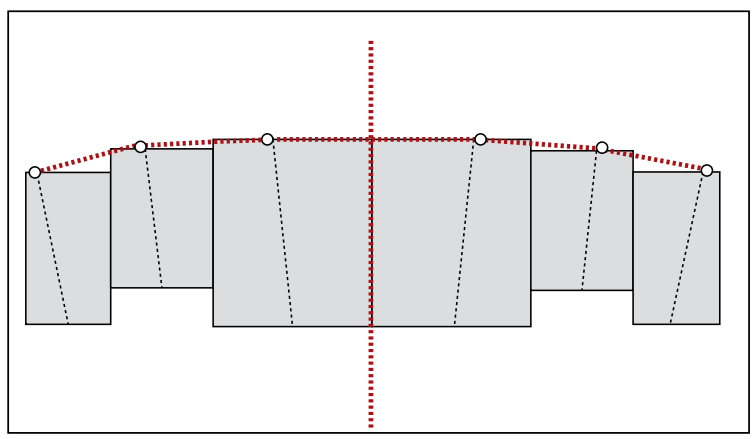

FIGURA 7 - Forma côncava da linha cervical.

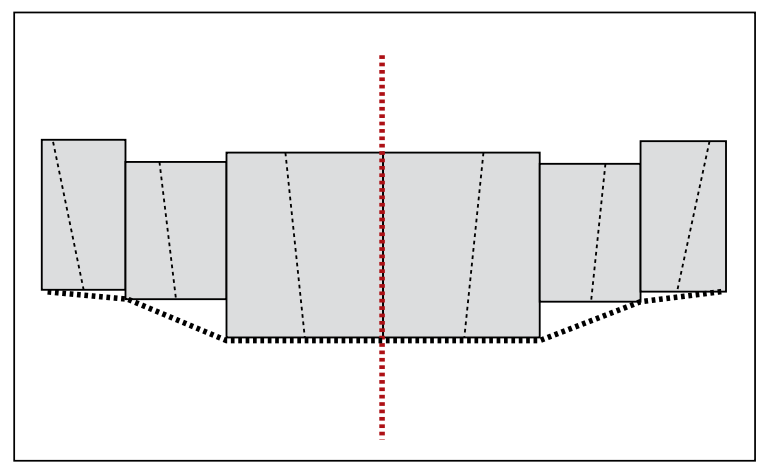

FIGURA 9 - Linha incisal com forma de "prato fundo". 
o tamanho dos dentes, inclinações dentárias, fatores eruptivos e inclinação do plano oclusal também podem alterar o desenho. O termo mais utilizado quando a linha incisal forma um "prato invertido" é o "sorriso invertido". A linha passa a ser côncava em relação ao plano oclusal frontal, dando uma aparência envelhecida e antiestética. A classificação da linha incisal também pode utilizar a nomenclatura côncava ("prato invertido"), plana ("prato raso") e convexa ("prato fundo"). Outros termos bastante utilizados para descrever a linha incisal são: "arco

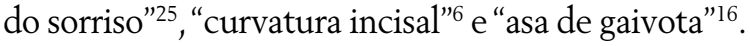

\section{LINHA DOS PONTOS DE CONTATO}

O contato interdentário dos dentes anterossuperiores é feito de forma descendente a partir do canino. $\mathrm{O}$ contato entre canino e incisivo lateral se posiciona mais alto do que o contato entre o incisivo lateral e o central; o contato entre os incisivos centrais se posiciona mais baixo ainda. Esses pontos de contatos devem ser justos, a menos que exista uma discrepância no diâmetro mesiodistal da coroa ${ }^{2}$. A posição do contato interdentário está relacionada à posição e morfologia do dente ${ }^{16}$. Sendo assim, a linha que une esses pontos será paralela à linha incisal, quando não houver uma discrepância entre tamanho, formato e angulação dos dentes anteriores. Embora exista um ponto de contato toda vez que um dente encosta no outro, o ideal é quando esse contato acontece em uma área mais larga do que um ponto, formando um espaço conector. Os espaços conectores são as áreas onde os dentes parecem se tocar. Como será visto adiante, esse fato repercute favoravelmente na estética dentária. Para fins práticos, quando o contato dentário se der em uma área ao invés de um ponto, consideraremos o local mais apical como a referência para o ponto de contato (Fig. 10).

\section{LINHA PAPILAR}

A linha papilar é formada pelas pontas das papilas gengivais que ficam entre caninos e incisivos

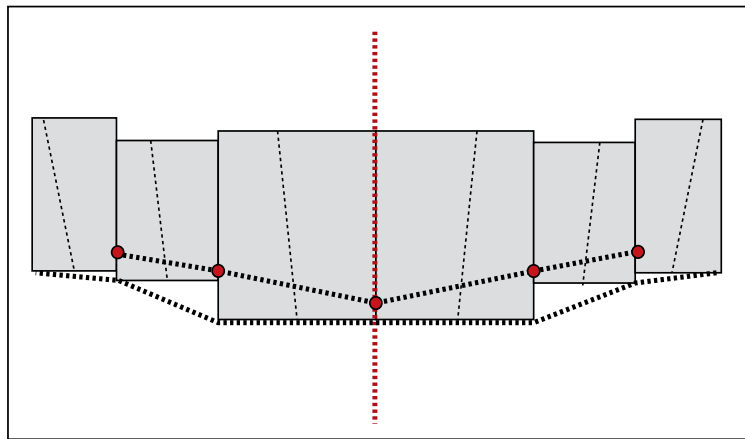

FIGURA 10 - Linha dos pontos de contato. Essa linha deve guardar um certo paralelismo com a linha incisal.

laterais superiores e incisivos laterais e incisivos centrais superiores. Não existem estudos que avaliaram a altura padronizada dessa relação. Em outras palavras, não existe definição de um modelo ideal da relação entre a altura das papilas. Entretanto, baseado em trabalhos que fizeram a avaliação da altura ideal nos incisivos centrais e a relação que a altura da ponta das papilas tem com o posicionamento e o tamanho dos dentes ${ }^{13,27}$, pode-se deduzir que uma linha ideal seria paralela à linha formada pelos pontos de contato. Explicando melhor, segundo o trabalho de Kurth e Kokich ${ }^{13}$, a papila nos incisivos centrais superiores preenche metade do tamanho desses dentes, quando em condições normais. Sendo assim, seria de se esperar que esse padrão se repetisse para incisivos laterais e caninos. Como o incisivos laterais são menores do que os incisivos centrais, e a papila deve preencher a metade da altura da sua coroa, a posição da papila entre incisivo central e lateral deve ficar apical à dos incisivos centrais, assim como a papila do incisivo lateral e canino (Fig. 11).

\section{Faixa dos conectores}

O local onde os dentes anteriores parecem se tocar é chamado de espaço conector. Como dito anteriormente, existe uma diferença entre o espaço conector e ponto de contato. Os pontos de contato são pequenas áreas onde os dentes se encostam. Os conectores são mais largos, amplos e podem ser definidos como zonas em que dois dentes 


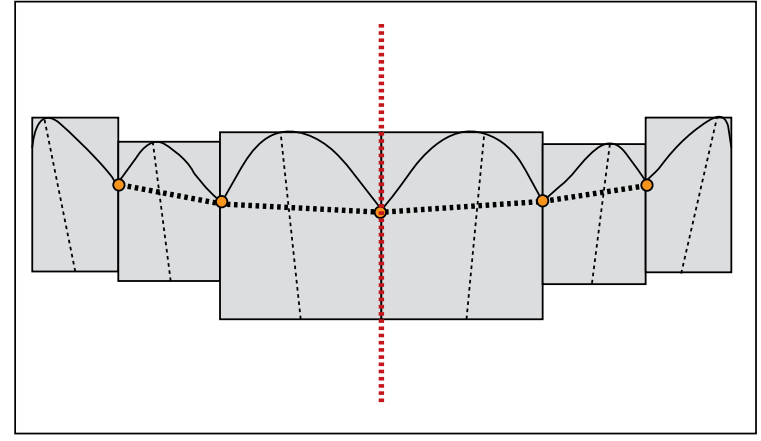

FIGURA 11 - Linha papilar. Representa a ponta das papilas gengivais.

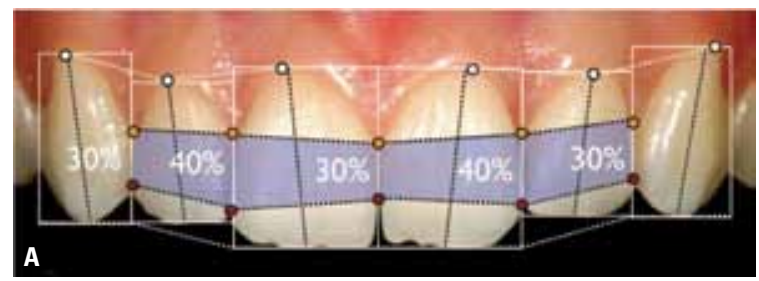

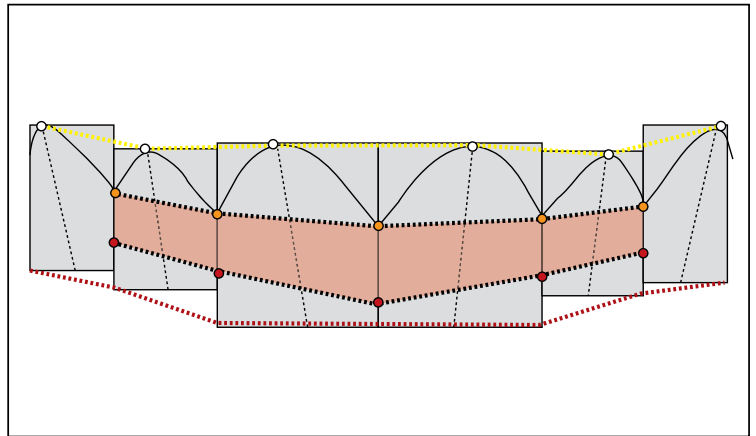

FIGURA 12 - Faixa dos conectores. Essa faixa é delimitada pelas linhas dos pontos de contato e linha papilar. 0 desenho da faixa lembra a forma de uma "asa delta".

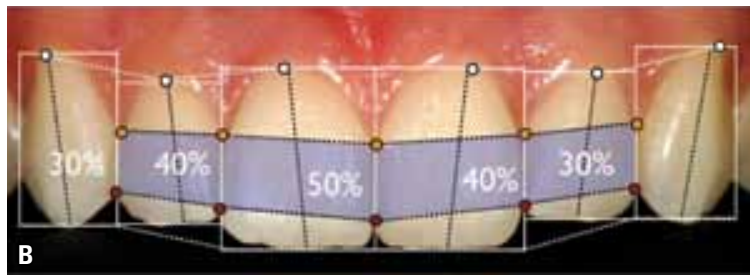

FIGURA 13 - Proporção desfavorável da "faixa de conectores" 30-40-30-40-30 (A). Um simples recontorno com acréscimo de resina composta entre os incisivos centrais proporcionou a formação de uma "faixa de conectores" favorável: 30-40-50-40-30 (B).

adjacentes parecem se tocar. A melhor relação estética dos dentes anteriores é a que segue a regra do espaço conector 50-40-30 ${ }^{19}$. Essa regra define que o espaço conector entre os incisivos centrais seja de $50 \%$ do tamanho desse dentes. O espaço conector ideal entre o incisivo central e o lateral é $40 \%$ do comprimento dos incisivos centrais e o espaço conector entre incisivo lateral e canino é 30\% da mesma referência. Embora Morley e Eubank ${ }^{19}$ não tenham definido os pontos referenciais para a determinação do espaço conector, pode-se criar essas referências a partir dos pontos de contato e papila gengival. Portanto, toda vez que não existir espaço negro ou diastema entre dois dentes, sendo esse preenchido pela papila gengival, a área dos conectores será delimitada pela ponta das papilas e os pontos de contato. Sendo assim, utilizando a linha das papilas e a linha dos pontos de contato como referência, teremos uma faixa que se chamará "faixa dos conectores". O desenho dessa faixa lembra a forma de uma "asa delta" (Fig. 12). Pequenas alterações nessa faixa podem fazer diferença na estética dentária. O recontorno dentário pode aumentar ou diminuir o espaço conector, dando uma melhor configuração dessa faixa (Fig. 13).

\section{Aplicação clínica}

A avaliação clínica do DRED com as quatro linhas e a faixa de conectores permitirá a utilização de um "check list" que poderá detectar os erros de posições dentárias e as suas relações com a gengiva. Com a observação do formato de cada linha, cria-se um planejamento que terá como foco a correção dos defeitos, a harmonização das linhas e a posterior avaliação dos resultados conseguidos. Essa avaliação facilita o diagnóstico e torna mais fácil e prática a detecção de problemas para todos os profissionais que tratam de problemas estéticos (Fig. 14).

\section{Análise labial}

Além dos dentes, o DRED também envolve os lábios. Com a avaliação labial, chega-se às seis linhas horizontais do sorriso, isto é, além das quatro linhas dentogengivais, somam-se as linhas dos 

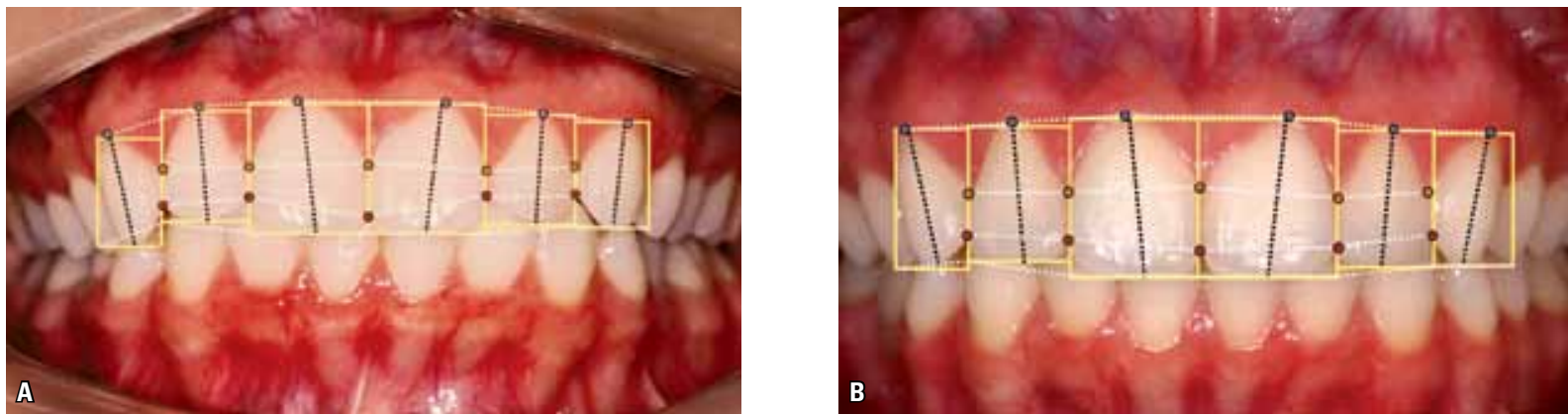

FIGURA 14 - "CHECK LIST" - Linha cervical: côncava (acentuada) e assimétrica. Linha incisal: forma de "prato fundo" invertido (côncava) e assimétrica. Faixa de conectores: 30\% (13/12) - 20\% (12/11) - 40\% (11/21) - 20\% (21-22) - 20\% (22/23) (A). "CHECK LIST" - Linha cervical: côncava (suave) e simétrica. Linha incisal: forma da "prato fundo" (convexa) e simétrica. Faixa de conectores: $30 \%(13 / 12)-35 \%(12 / 11)-40 \%(11 / 21)-35 \%(21 / 22)-30 \%(22 / 23)(B)$.

lábios superior e inferior. Tanto o lábio superior quanto o inferior interferem de forma marcante na beleza do sorriso. Individualmente, cada lábio irá influenciar no conjunto dentolabial e, juntos, irão criar desenhos que determinarão a exposição dentária aparente. $\mathrm{O}$ afastamento labial que ocorre durante o sorriso permitirá a exposição das estruturas dentárias e gengivais durante esse ato. Esse afastamento pode ser chamado de "descortinamento labial", uma vez que será esse descortinamento que dará a oportunidade aos trabalhos odontológicos estéticos serem mostrados (Fig. 15). O descortinamento labial é o que proporciona a avaliação da relação da estética branca (dentes) e rósea (gengiva) entre si e com os lábios. A relação tridimensional que essas estruturas guardam umas com as outras é o que causará ou não o efeito de agradabilidade.

Esse conceito é fundamental, pois leva à necessidade de se conhecer uma série de fatores que influenciam esse descortinamento. A maior ou menor exposição dentária será influenciada pelo descortinamento labial e todos os fatores intrínsecos a ele, como a sua formação, estágios, fases e envolvimento labial. Sendo assim, antes de iniciar a avaliação das linhas dos lábios superior e inferior, serão mostrados os fatores que interferem no sorriso.

\section{Formação do sorriso}

O sorriso pode ser definido como uma mudança

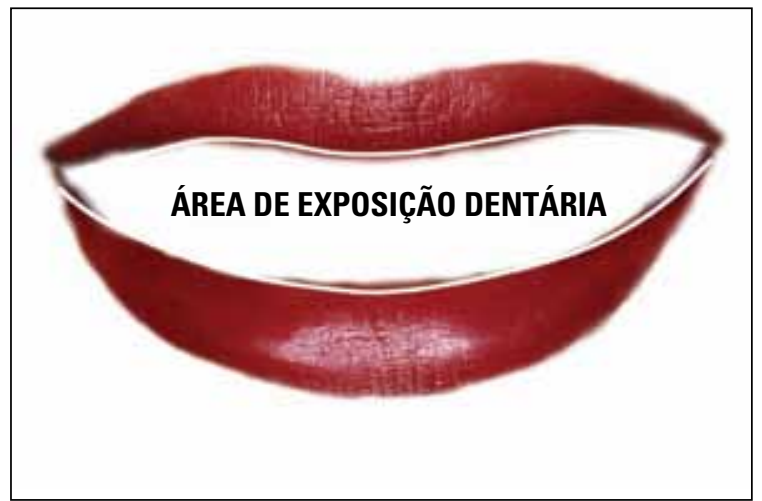

FIGURA 15 - “Descortinamento labial”.

na expressão facial, que envolve o brilho dos olhos, uma curvatura superior dos cantos dos lábios, a não emissão de som e menos distorção das formas dos músculos do que uma risada ${ }^{12}$. Inicia-se nas comissuras e se estende lateralmente; os lábios inicialmente podem permanecer em contato, exceto nas pessoas que apresentam ausência de selamento labial passivo ou lábio superior curto. À medida que o sorriso se expande, os lábios se separam, as comissuras curvam-se para cima e os dentes são expostos. Os maxilares são separados e desenvolve-se um espaço negro entre os dentes inferiores e superiores que é conhecido como espaço negativo ${ }^{18}$. No sorriso, a altura do lábio superior diminui e a largura da boca aumenta numa variação de $23 \%$ a $28 \%$ com relação ao lábio em repouso ${ }^{26}$. 
Não se deve superestimar a simetria da atividade muscular. Em pessoas normais, observa-se uma variabilidade individual da função motora na comparação lado a lado em um mesmo indivíduo. Medições combinadas tanto da mobilidade da pele ou quanto da atividade muscular indicam que, na face humana, existe em média uma assimetria de $6 \%$ entre os lados ${ }^{4}$.

\section{Estágios do sorriso}

$\mathrm{Na}$ análise do sorriso deve-se observar os seus estágios. Na sua formação existem dois estágios: o primeiro (sorriso voluntário) eleva o lábio superior em direção ao sulco nasolabial pela contração dos músculos elevadores que se originam neste sulco e têm inserção no lábio. Os feixes mediais elevam o lábio na região dos dentes anteriores e os laterais na região dos dentes posteriores. O lábio então encontra resistência devido ao tecido adiposo das bochechas. O segundo estágio (sorriso espontâneo) inicia-se com maior elevação tanto do lábio como do sulco nasolabial sob a ação de três grupos musculares: o elevador do lábio superior, com origem na região infraorbital; o músculo zigomático maior e as fibras superiores do bucinador ${ }^{23}$. A aparência de olhos semicerrados deve acompanhar o estágio final e representa a contração da musculatura periocular (músculos orbiculares dos olhos) para apoiar a elevação máxima do lábio superior através da prega nasolabial. $\mathrm{O}$ olhar semicerrado que acompanha o sorriso máximo é um gatilho muscular da face que ativa os centros cerebrais na região temporal anterior que regula a produção das emoções agradáveis. Assim, sem essa ação final de semicerramento dos olhos, o sorriso perceptível de felicidade, provavelmente é um falso sorriso sem alegria da pessoa que está sorrindo ${ }^{9}$ (Fig. 16).

\section{Fases do sorriso}

Além dos estágios, o sorriso segue fases. Essas fases se dão em três etapas. A primeira é chamada fase inicial de "pico", que corresponde ao período em que os lábios saem de uma posição neutra até a posição de máxima contração dos lábios durante o sorriso espontâneo. Nessa fase, a largura da boca aumenta e a altura do lábio diminui, as comissuras se movem para cima e para o lado nas mesmas proporções, sendo que a direção do movimento desses pontos apresenta grande variabilidade entre os indivíduos. Essa é a fase mais curta do ciclo e leva em média menos de 0,5 segundos. A segunda fase é a de sustentação labial. É nessa fase que o sorriso se mantém dependente do estímulo. A duração dessa fase é muito variável porque depende da vontade de cada indivíduo. A última fase é a de declínio, na qual os lábios voltam a se fechar. A
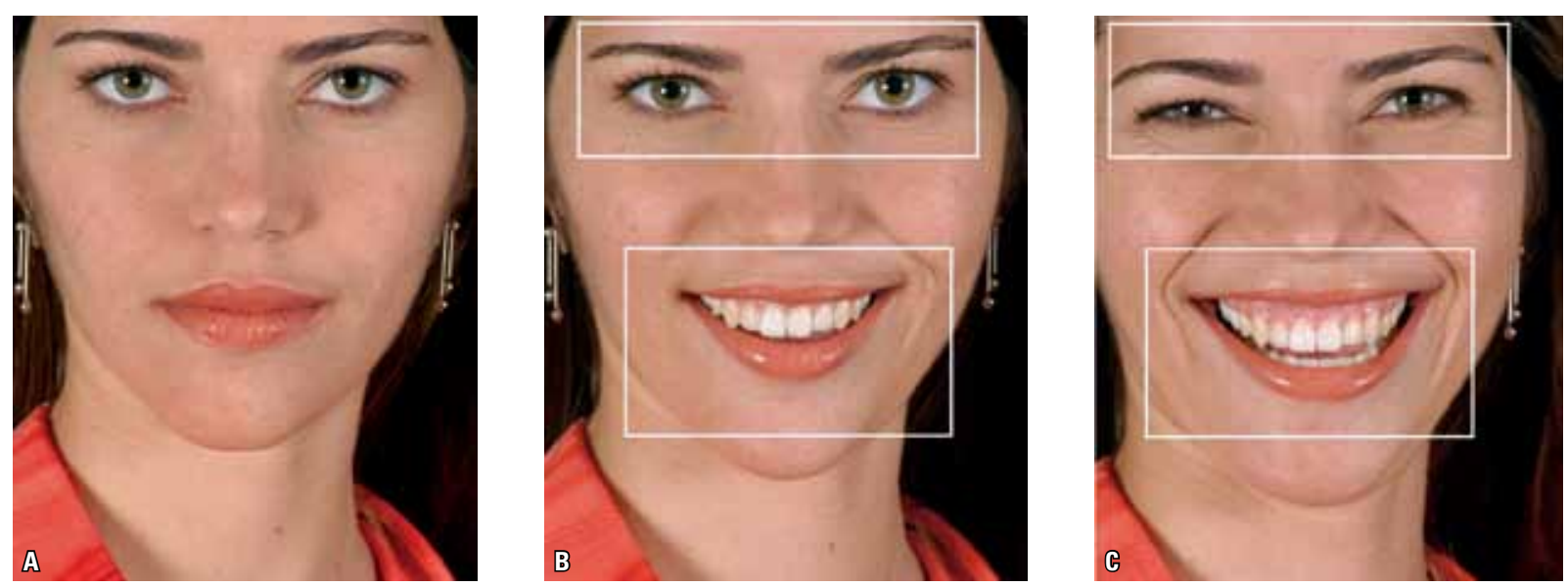

FIGURA 16. Posição de repouso (A). Primeiro estágio do sorriso - Sorriso social (B). Segundo estágio do sorriso - Sorriso espontâneo. Notar que neste estágio a paciente está com o olhar semicerrrado (C). 
duração dessa fase costuma ser maior do que a da fase inicial de pico, mas, assim como a de sustentação, não é possível mensurar o seu tempo devido à mesma estar sujeita a um estímulo. Avaliando o ciclo do sorriso, observa-se que a única fase reproduzivel é a inicial. Diferente das outras fases que podem ser influenciadas pela vontade de cada indivíduo, a fase de pico depende apenas do estímulo inicial que provoca o sorriso, sendo, porém, de curtíssima duração ${ }^{26}$. Esse fato prejudica a obtenção de imagens estáticas, como as fotográficas, pois torna quase impossível o registro do sorriso máximo obtido durante a primeira fase. É por isso que vários autores contraindicam a avaliação do sorriso com imagens fotográficas, indicando que a melhor maneira para o registro é através de filmagem ${ }^{1,24}$.

\section{Estímulo e registro do sorriso}

Embora já se tenha catalogado 18 tipos de sorriso $^{9}$, o que interessa diretamente à Odontologia é aquele que expressa alegria. Essa é a forma de sorriso conhecida como Duchenne, no qual ocorre uma contração da musculatura orbicular dos olhos em combinação com o tracionamento do canto do lábio pelo músculo zigomático maior e é, entre os tipos de sorriso, o que melhor demonstra contentamento ou felicidade. É o sorriso espontâneo ${ }^{9}$. Sendo assim, o sorriso que expressa prazer é o tipo que os profissionais buscam registrar. Para esse tipo de registro é necessário um estímulo. Nesse caso, o estímulo é um problema, uma vez que o que é engraçado para um pode não ser para outro. A dificuldade de se obter fotografias que representem o sorriso natural do paciente, na prática clínica, foi observada por Rigsbee et al. ${ }^{22}$, que relataram que a interação do profissional que está fotografando e o paciente não deve ser subestimada e sugeriram o uso de frases para se obter o registro. Esse método também é indicado por Zachrisson ${ }^{30}$, que sugere a utilização da palavra "cheese" para simular a exposição do incisivo durante o sorriso. Para a obtenção do registro da posição de repouso, o autor recomendou que os dentes estivessem ligeiramente afastados e os tecidos moles peribucais, assim como a postura mandibular, estivessem relaxados ${ }^{30}$. Embora a utilização de frases possa ser útil, a melhor maneira para a obtenção do sorriso é o estímulo cômico. $\mathrm{O}$ uso de vídeos, fotografias ou a própria capacidade cômica do profissional podem ser adotados para provocar o estímulo. $\mathrm{O}$ importante é que o estímulo provoque um sorriso que expresse prazer. Já para as avaliações que envolvam a relação de dentes com o lábio superior, recomenda-se, apesar de possiveis questionamentos, a pronúncia da letra "i" de uma maneira desinibida e exagerada. Dessa forma, pode-se obter a elevação máxima do lábio superior ${ }^{21}$.

O registro do sorriso é outro problema. O ideal é que sejam feitos registros estáticos (fotografias) e dinâmicos (filmagem). Nos registros estáticos, a obtenção de imagens deve incluir enquadramentos aproximados nos planos frontal, sagital e oblíquo. Nos registros dinâmicos, a filmagem deve ser gravada e repassada para um computador, e a melhor imagem escolhida ${ }^{24,25}$. Na avaliação, pode ser dada preferência ao sorriso social ou espontâneo de elevação máxima do lábio superior. $\mathrm{O}$ importante é que o registro inicial seja do mesmo tipo do registro final, para que se possa avaliar as diferenças sem contar com as interferências dos estágios. Explicando melhor, se o primeiro registro foi no estágio 1 o registro final também deve ser feito nesse mesmo estágio.

\section{LINHA DO LÁBIO SUPERIOR}

A linha do lábio superior representa a borda inferior do lábio. Essa linha é a que dita a exposição dos dentes superiores. Não apenas os dentes anteriores, mas também os dentes posteriores, têm as suas exposições limitadas por essa linha. Vários autores recomendam que, durante o sorriso, a posição da borda inferior do lábio superior deve coincidir com a margem gengival do incisivo central superior ${ }^{14,15,17}$. No entanto, outros autores consideram que um sorriso poderia ser aceitável esteticamente com a exposição de até $2 \mathrm{~mm}$ 
de tecido gengival ${ }^{3,10,30}$. Essa diferença de opiniões leva à descrição de conceitos inadequados e confusos, que não ajudam na padronização de classificações do sorriso. Embora a maneira mais simples de classificar a linha do sorriso - que é o relacionamento entre os incisivos superiores e o lábio superior - seja através da altura (baixo, médio e alto), ainda encontram-se inadequações na descrição dos parâmetros. Por exemplo, a classificação de alturas do sorriso descrita por Tjan et al. ${ }^{29}$, e utilizada por Dong et $\mathrm{al}^{8}{ }^{8}$, considera como alto todo sorriso no qual a coroa do incisivo central superior esteja totalmente exposta. Desse modo, um sorriso que apresente uma faixa de tecido gengival de apenas $1 \mathrm{~mm}$ vai receber a mesma classificação de um sorriso que apresente, por exemplo, $5 \mathrm{~mm}$ de exposição de tecido gengival. O mesmo pode ser dito sobre a classificação descrita por $\mathrm{Teo}^{28}$, que classifica como Classe I todos os sorrisos nos quais a face vestibular do incisivo está totalmente exposta, independentemente da quantidade de tecido gengival aparente. De forma análoga, a classificação do sorriso quando o lábio superior não expõe os incisivos superiores também é confusa na descrição de alguns autores $^{3,11}$. Na classificação de Goldstein ${ }^{11}$, um sorriso que apresente o lábio superior cobrindo apenas $1 \mathrm{~mm}$ da coroa do incisivo central superior vai receber a mesma classificação de um que apresente, por exemplo, o lábio superior cobrindo mais que a metade ou até mesmo toda a coroa do incisivo central superior.

Como já foi dito, o ideal é que a altura da linha do sorriso seja classificada usando-se como referência o relacionamento entre a borda inferior do lábio superior e a margem gengival do incisivo central superior. No entanto, deve ser estabelecido um limite de $2 \mathrm{~mm}$ acima e abaixo da margem gengival, sendo estabelecidas as três classes de altura do sorriso: alto, médio e baixo (Fig. 17). Sendo assim, um ponto que pode ser considerado positivo é que, com uma diferença de $4 \mathrm{~mm}$, a diferenciação de sorrisos altos e baixos, que são os que normalmente motivam o paciente a procurar tratamento, é facilitada clinicamente ${ }^{21}$. Além disso, cria-se uma diferenciação numérica entre as alturas, facilitando a mensuração da classificação.

A altura do sorriso é influenciada pela idade e pelo gênero. Quanto mais velho o indivíduo, maior a tendência para que apresente o tipo baixo ${ }^{7}$. Essa informação se torna clinicamente relevante, uma vez que sorrisos altos tendem a se tornar médios com a idade, e os sorrisos baixos tornam-se cada vez mais baixos. Em outras palavras, existe uma possibilidade de autocorreção para os sorrisos "gengivais" com o passar do tempo, o mesmo não acontecendo com os sorrisos baixos.

O gênero também parece influenciar na altura do sorriso. Embora não existam muitos estudos a respeito do assunto, o trabalho de Puppin ${ }^{21}$ mostra que existe uma maior tendência para as mulheres apresentarem a linha do sorriso média $(55,9 \%)$ e alta $(37,7 \%)$, e os homens a média (54\%) e baixa $(23,8 \%)$. Esses achados são semelhantes aos valores encontrados no trabalho de Peck, Peck e Kataja ${ }^{20}$, que também observaram que os sorrisos médios $(52,2 \%)$ e altos $(32,5 \%)$ são mais comuns nas mulheres, e os sorrisos médios (48\%) e baixos (33\%) nos homens.

A linha do sorriso pode ser considerada como fator determinante na avaliação da estética bucal. Os resultados estéticos dos tratamentos ortodônticos sempre guardam uma forte relação com essa linha. Não é incomum a finalização de

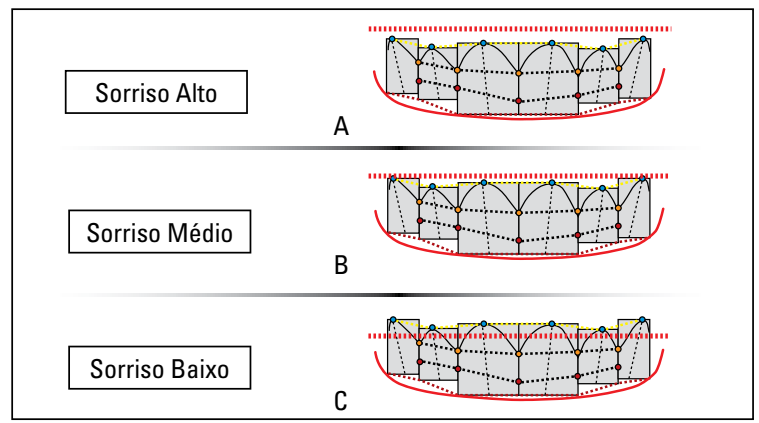

FIGURA 17 - Sorriso Alto (A); Sorriso Médio (B) e Sorriso Baixo (C). 
tratamentos ortodônticos ser comprometida pela altura do sorriso. Tanto o sorriso alto quanto o baixo podem comprometer os resultados. Esse talvez seja o grande desafio da Ortodontia contemporânea na busca da excelência. A integração entre as especialidades odontológicas precisará ser ampliada também para áreas médicas que possam interferir positivamente na solução de problemas estéticos bucais que estejam comprometidos pela influência negativa da linha do sorriso (em outras palavras, pela atuação da linha do lábio superior). Intervenções médicas e odontológicas que sejam capazes de corrigir a influência labial negativa serão sempre bem-vindas. Essa atuação integrada de equipes profissionais trará novas possibilidades na obtenção de melhores resultados, ampliando as possibilidades de tratamento, criando, talvez, uma maior demanda para a solução de problemas que envolvem a estética bucal, facial e dentária.

\section{LINHA DO LÁBIO INFERIOR}

Embora a influência do lábio inferior no sorriso seja menos estudada do que a do lábio superior, ela não é menos importante. É o conjunto formado pelos lábios superior e inferior que irá proporcionar o descortinamento labial.

Em geral, é a forma do lábio inferior e as bordas incisais dos dentes anteriores superiores e inferiores que criam um arranjo agradável ou desagradável do sorriso ${ }^{25}$. O importante é que o plano incisal superior e a forma do lábio inferior mantenham uma relação harmoniosa ${ }^{30}$. Essa harmonia é representada pelo paralelismo do arco formado pelas bordas incisais e oclusais dos dentes superiores com a borda superior do lábio inferior.

Deve haver uma harmonia entre a curvatura da borda incisal dos dentes anterossuperiores com a curvatura da borda superior do lábio inferior durante o sorriso voluntário ${ }^{11}$. Esse relacionamento entre as bordas incisais de caninos e incisivos superiores com o lábio inferior é chamado de arco do sorri$\mathrm{so}^{10,24}$. O ideal é que a curvatura das incisais fiquem paralelas ao lábio inferior e as incisais ligeiramente afastadas ou tocando levemente o lábio. Entretanto, isso só é possivel quando o lábio inferior cria uma curvatura natural, com os cantos da boca voltados para cima e as bordas incisais acompanham essa curvatura. Em outras palavras, para que um efeito agradável seja possível, é necessário que as estruturas dentárias e labiais estejam simétricas. $\mathrm{Ou}$ seja, caso os lábios ou dentes limitem o paralelismo entre si, o arco do sorriso não será possível. A assimetria labial é também um fator limitante para essa harmonia entre dentes e lábios.

Como já foi dito, o ideal ou desejável é que a linha formada pelas bordas incisais dos dentes anteriores crie uma forma de "prato fundo", onde os incisivos centrais se posicionem mais inferiormente aos incisivos laterais e caninos, e que se mantenham em harmonia com as outras linhas do sorriso $^{5}$ (Fig. 18).

Essa configuração varia com a idade: conforme a idade avança, a forma de "prato fundo" vai se alterando, dando lugar a uma nova forma de "prato raso" ou de "prato invertido". Isto é, a linha que contorna a borda incisal vai se tornando mais plana ou côncava. O desgaste das bordas incisais, com o tempo, cria essas novas formas. O conhecimento dessas características cria a possibilidade de rejuvenescer ou envelhecer o sorriso. A alteração das "formas do prato" possibilitará esse efeito ${ }^{5}$ (Fig. 19).

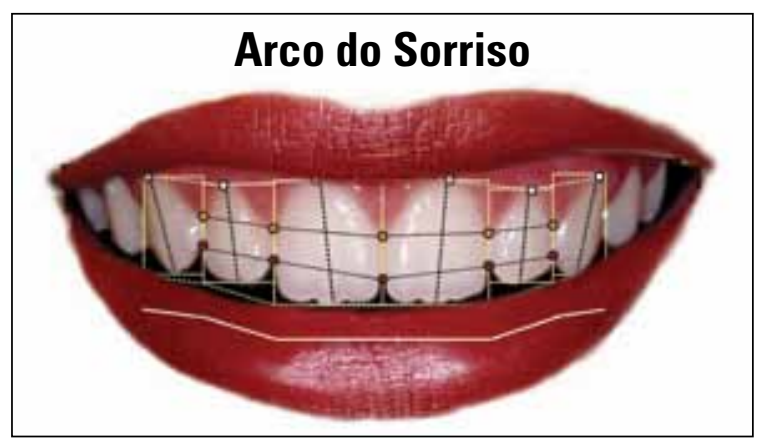

FIGURA 18 - 0 posicionamento vertical dos incisivos e caninos superiores forma uma curvatura, cuja linha que contorna essa relação lembra um desenho de "prato fundo". 
Deve ficar claro que a relação ideal de paralelismo entre dentes superiores e lábio inferior é ditada pelo lábio. O padrão de contração dos lábios inferiores e a sua relação com os dentes é bem menos uniforme do que nos lábios superiores. Enquanto na relação do lábio superior com os dentes superiores pode-se estabelecer três posições definidas em relação à linha do sorriso (alta, média e baixa), com o lábio inferior isso não é possível. A própria dinâmica do sorriso complica essa avaliação. A possibilidade do indivíduo abrir mais ou menos a boca dificulta uma avaliação padronizada. Algumas vezes os dentes superiores podem tocar o lábio inferior (posição contativa), outras vezes manterem-se afastados (posição não-contativa) e outras serem cobertos pelo lábio (posição coberta $)^{10}$. Essa situação pode variar entre indivíduos e até mesmo em uma mesma pessoa, dependendo da abertura bucal. As contrações musculares do lábio inferior também alteram essa relação. Músculos como o risório, mentoniano, triangular e quadrado do lábio inferior são os responsáveis pela contração do lábio inferior e a sua maior ou menor ação durante o sorriso interfere na contração labial, assim como na simetria labial ${ }^{23}$. Variações na contração e intensidade dos grupos musculares exercem um importante papel na criação de diferentes sorrisos. Contrações vigorosas puxam o lábio inferior para baixo, aumentando a exposição dentária. Indivíduos com grandes contrações musculares do lábio inferior costumam expor também os dentes inferiores (Fig. 20).

Essa situação merece atenção, uma vez que as necessidades e possibilidades do tratamento estético mudam de perspectiva, pois costuma-se avaliar a relação dos lábios com os dentes superiores e não com a arcada completa. Buscar, nesses casos, o paralelismo entre a linha incisal e o lábio inferior (arco do sorriso) é totalmente inviável e mostranos que o estabelecimento de regras e objetivos estéticos levando em consideração o lábio inferior não possibilita padronizações. Outra situação que também cria dificuldades para a obtenção do arco do sorriso é quando o lábio inferior contrai de forma invertida. Explicando melhor: a contração do lábio inferior é maior na região dos caninos do que na área dos incisivos, provavelmente por uma maior atuação do músculo risório. Quando o lábio superior também contrai dessa mesma forma, cria-se uma aparência de "espelhamento" entre os lábios. Normalmente, esse contorno labial inferior é acompanhado por uma linha de sorriso baixa e o desenho formado pelos lábios lembra o desenho do "símbolo do infinito" ( $\infty)$ (Fig. 21). Esse tipo de desenho do sorriso indica um prognóstico desfavorável para os tratamentos da estética bucal.
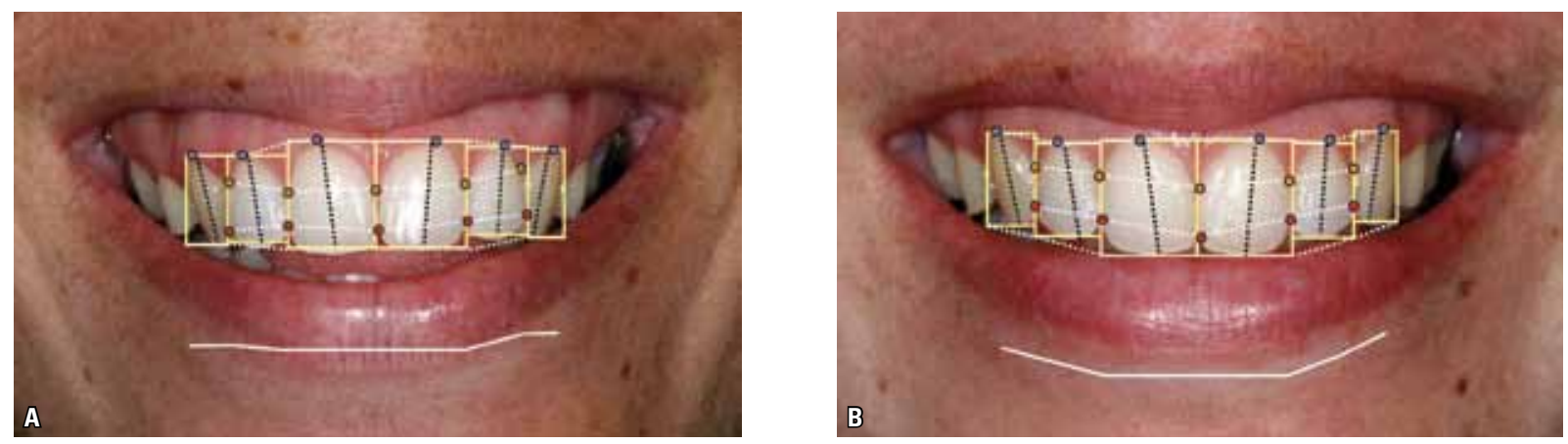

FIGURA 19 - 0 reposicionamento vertical dos incisivos e caninos superiores, após um tratamento ortocirúrgico de impactação e giro da maxila, proporcionou um melhor relacionamento das bordas incisais dos dentes anterossuperiores com o lábio inferior, criando a forma de "prato fundo". Essa linha convexa dá um aspecto estético mais agradável e jovial. 


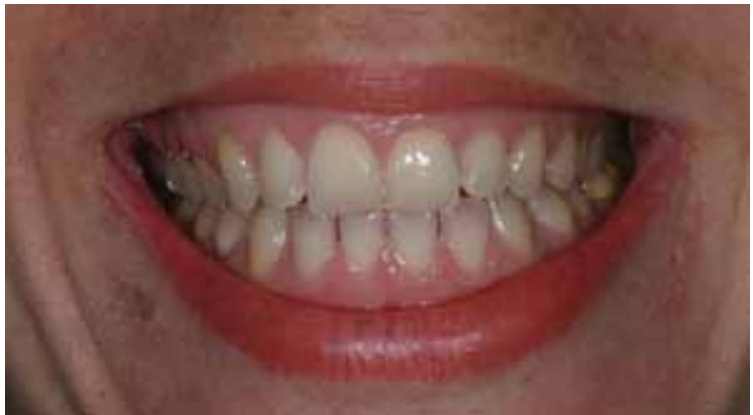

FIGURA 20 - Contração excessiva do lábio inferior expondo completamente os incisivos inferiores.

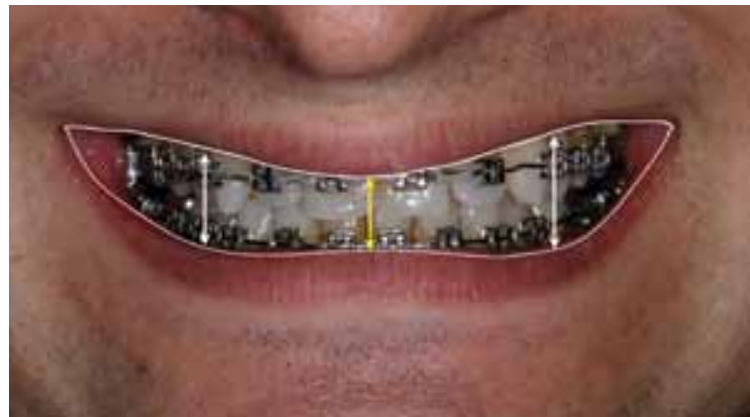

FIGURA 21 - "Espelhamento" da forma do lábio inferior com o lábio superior. Notar que a região do lábio inferior (seta amarela) está mais próxima do lábio superior do que nas regiões laterais (setas brancas). 0 desenho formado pelos lábios lembra o símbolo do infinito $(\infty)$.

trabalho, não devem ser ignorados, pois, junto com as seis linhas, permitirão uma ampla observação do sorriso, facilitando a sua compreensão e possibilidades de tratamento.

\section{AGRADECIMENTO}

Adilson Torreão, Adilson Torreão Filho, Aldino Puppin, Isana Álvares, Jonas Capelli Jr., Marco Antônio Almeida e Vera Cosendey. seus pacientes, permitindo que o diagnóstico esteja integrado com o prognóstico, dando uma visão realista dos resultados que podem ser obtidos. Nessa perspectiva, as seis linhas horizontais do sorriso vêm ao encontro desse propósito, uma vez que a análise dessas linhas facilita o entendimento das características intrínsecas do sorriso e traz para cada profissional uma melhor visão das suas chances de sucesso. Entretanto, sabemos que, na avaliação do sorriso, não é suficiente a observação apenas dessas seis linhas, muitos outros fatores também devem ser levados em consideração. Corredor bucal; quantidade de dentes expostos no sorriso; análise facial frontal, oblíqua e de perfil; e a relação entre a posição de repouso e fala com o sorriso são fatores que também devem ser observados para um melhor diagnóstico da estética bucal. Embora esses componentes não tenham sido analisados nesse
Enviado em: março de 2009 Revisado e aceito: dezembro de 2009 


\title{
Esthetics in Orthodontics: Six horizontal smile lines
}

\begin{abstract}
Introduction: The analysis of the smile is an important step for the diagnosis, planning, treatment and prognosis of any dentistry treatment involved with aesthetic goals. The evaluation of intrinsic characteristics of the smile is a necessary procedure so that one can be able to perform consistently a orthodontic treatment, requiring, for this aim, recognize the components and factors which interfere in these characteristics. Objective: The objective of this paper is to present the six horizontal lines of the smile and its importance for achieving desired results in orthodontic treatment. Conclusion: The analysis of the six horizontal lines of the smile facilitates the understanding of intrinsic characteristics that interfere with oral aesthetics. Furthermore, the harmonization of these lines brings to each professional a greater chance of success in those treatments that include cosmetic purposes.
\end{abstract}

Keywords: Orthodontics. Esthetics in Orthodontics. Dental esthetics. Oral esthetics. Smile.

\section{REFERÊNCIAS}

1. Ackerman MB, Ackerman JL. Smile analysis and design in the digital era. J Clin Orthod. 2002 Apr;36(4):221-36.

2. Andrews LF. Straight-Wire: the concept and appliance. San Diego: Wells; 1989.

3. Arnet GW, Bergman RT. Facial keys to orthodontic diagnosis and treatment planning. Part I. Am J Orthod Dentofacial Orthop. 1993 Apr;103(4):299-312.

4. Burres SA. Facial biomechanics: the standards of normal. Laryngoscope. 1985 Jun;95(6):708-14.

5. Câmara CALP. Estética em Ortodontia: diagramas de referencias estéticas dentárias (DRED) e Faciais (DREF). Rev Dental Press Ortod Ortop Facial. 2006 nov/dez;11(6):130-56.

6. Chiche G, Pinault A. Artistic and scientific principles applied to esthetic dentistry. In: Chiche G, Pinault. A. Esthetics of anterior fixed prosthodontics. St. Louis: Quintessence; 1994. p. 13-32.

7. Cosendey V L. Avaliação do relacionamento entre o lábio superior e incisivos durante a fala e o sorriso. [dissertação]. Rio de Janeiro (RJ): Universidade do Estado do Rio de Janeiro; 2008.

8. Dong J, Jin $\mathrm{T}$, $\mathrm{Cho} \mathrm{H}$, Oh S. The esthetics of the smile: a review of some recent studies. Int J Prosthod. 1984 Jan;12(1):16-24.

9. Ekman P, Davidson RJ, Friesen WV. The Duchenne smile: emotion expression and brain physiology II. J Pers Soc Psychol. 1990 Feb;58(2):342-53.

10. Fowler P. Orthodontics and orthognatic surgery in the combinated treatment of an excessive gummy smile. New Zealand Dent J. 1999 Jun;95:53-4.

11. Goldstein RE. Estética em Odontologia. Rio de Janeiro: Ed. Guanabara Koogan; 1980

12. Grove PB. Webster's third new international dictionary of the English language. Springfield: G and C Merriam Company; 1961.

13. Kurth JR, Kokich VG. Open gingival embrasures after orthodontic treatment in adults: prevalence and etiology. Am J Orthod Dentofacial Orthop. 2001 Aug;120(2):116-23.

14. Legan HL, Burstone CJ. Soft tissue cephalometric analysis for orthognatic surgery. J Oral Surg. 1980 Oct;38(10):744-51.

15. Levine RA, McGuire M. The diagnosis and treatment of the gummy smile. Compend Contin Educ Dent. 1997 Aug:18(8):757-62, 764; quiz 766

16. Magne P, Belser U. Restaurações adesivas de porcelana na dentição anterior. Uma abordagem biomimética. São Paulo: Quintessence; 2003.

17. Marckley RJ. An evaluation of smiles before and after orthodontic treatment. Angle Orthod. 1993 Fall;63(3):183-9.
18. Mathews TG. The anatomy of a smile. J Prosthet Dent. 1978 Feb;39(2):128-34.

19. Morley J, Eubank J. Macro esthetic elements of smile design. J Am Dent Assoc. 2001 Jan;132(1):39-45.

20. Peck S, Peck L, Kataja M. Some vertical lineaments of lip position. Am J Orthod Dentofacial Orthop. 1992 Jun;101(6):51924.

21. Puppin FA. Avaliação quantitativa de medidas dento-faciais relacionadas à altura da linha do sorriso. [dissertação]. Rio de Janeiro (RJ): Universidade do Estado do Rio de Janeiro; 2002.

22. Rigsbee OH 3rd, Sperry TP, BeGole EA. The influence of facial on smile characteristics. Int J Adult Orthodon Orthognath Surg. 1988;3(4):233-9.

23. Rubin LR. The anatomy of a smile: its importance in the treatment of facial paralysis. Plast Reconstr Surg. 1974 Apr:53(4):384-7.

24. Sarver DM, Ackerman MB. Dynamic smile visualization and quantification: Part 1. Evolution of the concept and dynamic records for smile capture. Am J Orthod Dentofacial Orthop. 2003 Jul; 124(1):4-12.

25. Sarver DM. The importance of incisor positioning in the esthetic smile: smile arc. Am J Orthod Dentofacial Orthop. 2001 Aug;120(2):98-111.

26. Tarantili W, Halazonetis DJ, Spyropoulos MN. The spontaneous smile in dynamic motion. Am J Orthod Dentofacial Orthop. 2005 Jul;128(1):8-15

27. Tarnow DP, Magner AW, Fletcher P. The effect of the distance from the contact point to the crest of bone on the presence or absence of the interproximal dental papilla. J Periodontol. 1992 Dec;63(12):995-6.

28. Teo CS. An evaluation of the smiling lip line. Singapore Dent J. 1981 May;6(1):27-30.

29. Tjan AH, Miller GD, The JG. Some esthetics factors in a smile. J Prosthet Dent. 1984 Jan;51(1)24-8.

30. Zachrisson BU. Esthetic factors involved in anterior tooth display and smile: vertical dimension. J Clin Orthod. 1998;32(7):432-45

Endereço para correspondência

Carlos Alexandre Câmara

Rua Joaquim Fagundes 597, Tiro

CEP: 59.022-500 - Natal / RN

E-mail: cac.ortodontia@digi.com.br 